\title{
Taşkın Risk Haritasının Oluşturulması: Trabzon İli Vakfıkebir İlçesi Kirazlı Deresi Örneği
}

\author{
Esra ERTÜRK ${ }^{1}$, Nihat KAYA², Selçuk MERCAN³
}

\begin{abstract}
Özet
Bu çalışma kapsamında, proje alanı olarak seçilen Trabzon İli, Vakfıkebir İlçesi Kirazlı deresi için Hydrologic Engineering Center-River Analysis System (HEC-RAS) yazılımı ile kurulmuş 1 boyutlu ve 2 boyutlu hidrodinamik modellerle, Q500 debisi kullanılarak, elde edilmiş taşkın tehlike ve derinlik haritaları doğrultusunda en riskli durumu belirleyebilmek için taşkına maruz kalan alanların yer aldığı binalarda nüfus analizi yapılmıştır. Çalışma alanının Doğu Karadeniz Bölgesinde seçilme nedeni, hem meteorolojik olarak fazla yağış alması hem de topoğrafik açıdan taşkın riski taşımasıdır. Daha önce hazırlanan taşkın tehlike ve derinlik haritaları doğrultusunda; taşkından etkilenen insan sayısı, sosyo-ekonomik aktiviteler ve olası ekonomik zararların tahmin edilmesi amaçlanarak taşkından etkilenebilecek yapıların risk durumunu belirlenmeye çalışılmıştır. Taşkın risk durumu belirlenirken Geographic Information System (Arc-GIS) programı ile taşkın derinlik haritasında yer alan konutlar, fabrika, sera alanlarının, konumları ve o bölgede yaşayan nüfus sayısının belirlenmesinin ardından yapıların cinsine göre ekonomik zarar hesaplanmıştır. Yapıların toplam ekonomik zarar değerinin yapıların kendi alanlarına bölünmesiyle taşkın birim zararı hesaplanarak, hesaplanan bu değerlerin birim metrekareye düșen maksimum ve minimum zarar değerleri 0 ile 1 arasında normalize edilmiștir. Nüfus risk durumu içinde yine aynı metot kullanılarak, normalize edilmiş birim taşkın zararı ile nüfus toplanarak tașkın risk durumu belirlenmiștir. Taşkın risk yüzdelerinin belirlendiği bu çalışmada, taşkından etkilenen yapıların durumuna göre de kabul yöntemiyle yapılan standart sapma analizi sonucu tehlike risk dereceleri belirlenmiștir. Bu kapsamda yapılan çalışma sonucu, taşkın zararlarının etkilerini en aza indirmek maksadıyla derenin belirli kısımlarda gerekli taşkın kontrol yapıları ile mevcut sanat yapılarının yeniden yapılması veya iyileștirilmesi ve derenin düzenli olarak yılda bir defa yatak temizliğinin yapılmasının faydalı olacağı düşünülmektedir.
\end{abstract}

Anahtar Kelimeler: Taşkın, Risk, Modelleme, Arc-GIS

\footnotetext{
1İnşaat Yüksek Mühendisi, Devlet Su İşleri Genel Müdürlüğü, Ankara

İlgili yazar e-posta / Corresponding author e-mail: esradduru@gmail.com ORCID No: 0000-0003-4395-6056

${ }^{2}$ Doç. Dr. İnşaat Mühendisliği Bölümü, Fırat Üniversitesi, Elazığ

e-posta/ e-mail: nkaya@firat.edu.tr ORCID No: 0000-0002-9820-9587

ذİnşaat Müh. Bölümü, Gazi Üniversitesi, Ankara

e-posta/ e-mail: selcukmercn@gmail.com ORCID No: 0000-0001-5414-6062
}

Bu makaleye atıf yapmak için- To cite this article Ertürk, E., Kaya, N. ve Mercan, S. (2021). Taşkın Risk Haritasının Oluşturulması: Trabzon İli Vakfıkebir İlçesi Kirazlı Deresi Örneği. Afet ve Risk Dergisi, 4(1), 84-98. 


\title{
Determination of the Flood Risk Map: Case Study-Kirazlı Creek (Trabzon-Vakfikebir)
}

\begin{abstract}
In this study, population analysis has been carried out in buildings in order to determine the riskiest situation in line with the flood hazard and depth maps obtained by using Q500 flow rate, with 1 and 2 dimensional hydrodynamic models installed with Hydrologic Engineering CenterRiver Analysis System (HEC-RAS) software for Kirazlı Stream in Trabzon Province, Vakfikebir District, which was selected as the project area. The reason for choosing the study area in the Eastern Black Sea Region is that it receives excessive meteorological rainfall and has a flood risk in terms of topography. In line with the previously prepared flood hazard and depth maps; with the aim of estimating the number of people affected by the flood, socio-economic activities and possible economic damages, the risk status of the buildings that may be affected by the flood was tried to be determined. While determining the flood risk situation, the economic damage was calculated according to the type of the buildings, after determining the houses, factories, greenhouse areas, locations and the number of populations living in that region, on the flood depth map with the Geographic Information System (Arc-GIS) program. The flood unit loss is calculated by dividing the total economic loss value of the buildings by their own areas, and the maximum and minimum loss values per unit square meter of these calculated values are normalized between 0 and 1 . In the population risk situation, using the same method, the population was collected with the normalized unit flood damage and the flood risk situation was determined. In this study, in which the flood risk percentages were determined, according to the condition of the buildings affected by the flood, the standard deviation analysis made by the acceptance method determined the hazard risk degrees. As a result of the study carried out in this context, it is thought that it will be beneficial to rebuild or improve the existing art structures with the necessary flood control structures in certain parts of the stream and to clean the bed regularly once a year to minimize the effects of flood damages.
\end{abstract}

Keywords: Flood, Risk, Modeling, Arc-GIS

\section{Gİiș}

Taşkın, bir akarsuyun çeşitli sebeplerle yatağından taşarak çevresindeki yerleşim yerlerine, canlılara, altyapı tesislerine, tarım arazilerine zarar vermesi ve etkilediği bölgenin normal sosyoekonomik faaliyetlerini kesintiye uğratması halidir (URL-1). Ani taşkınlar, çöller de dâhil olmak üzere dünyanın herhangi bir yerinde ortaya çıkabilen ve dünyanın birçok yerinde görülen bir taşkın türüdür. Taşkın afetlerini yalnızca meteorolojik oluşumlara bağlı olarak ifade etmek mümkün değildir.

Dünya genelinde içinde bulunduğumuz zaman ve iklimsel değişimlere bağlı olarak akarsu havzaları içinde büyüyen yerleşimler, açılan yeni yollar ve kurulan yeni tesisler ile arazi yapısı değişmekte, elverişsiz tarım yöntemleri ile topraklar daha yoğun bir șekilde kullanılmakta, ormanlar ve meralar tahrip edilmekte, tüm bu koşullarda da taşkın afetleri daha büyük ve sık olarak görülmektedir (Özcan, 2007). Son yıllarda dünyada ve ülkemizde yaşanan sel ve su baskını gibi doğal afetler, kırsal alanlardan ziyade yağış-akış hızının fazla olduğu şehir merkezlerinde yaşanmakta olup plansız kentleşmeler veya altyapıdaki yetersizlikler nedeniyle bir doğal süreç olarak yağan mevsim normallerindeki yağmur bile șehir merkezlerinde büyük bir sel felaketine dönüşerek can ve mal kayıplarına dönüşebilmektedir (Sarı̈ül ve Turoğlu, 2020). 
Şehir taşkınlarının en büyük nedenlerinden biri betonlaşma ve altyapı yetersizliği sonucu yağış sularının kısa sürede deşarj edilememesidir. Yeşil alanlar ve betonlaşmamış yüzeyler zeminin geçirgenliğini arttırarak yağmur suyuna geçici depolama sağlar. Aksi durumda akışa geçen sular tehlike yaratır. Taşkınlara sebep olan diğer faktörler arasında yanlış arazi kullanımı da yer almakta olup özellikle bitki örtüsünün olmaması, yoğun yapılaşma gibi nedenlerle bölgenin hidrolojisini de değiştirmektedir. Ayrıca taşkın riskli alanlarda zemini yüksek tutmak yerine (dükkân, bazen depo) eksi katların inşasına izin verilmesi gibi olaylarda taşkına sebebiyet veren nedenlerdendir. Bütün bu faktörler göz önüne alındığında şehir sellerinin doğal bir afet olarak nitelendirilmesi yanında insan kaynaklı (antropojenik) olduğunu da belirtmek gerekmektedir. Ayrıca meydana gelecek selin vereceği zararında; şehre, bölgeye, gelişmişlik durumuna, alınan tedbirlere ve uygulanabilecek durum düzeyine göre değișeceğini de unutmamak gerekmektedir (Yılmaz ve Kaya, 2020).

Ani yağışlar zemin tarafından emilemeyerek yüzeysel akış halinde taşkına dönüştüğünden dolayı ani taşkınlar özellikle bir kurak devrenin son kısımlarında ortaya çıkabileceği iklim değişikliği sonucunda, ani taşkınların sayı ve şiddetlerinde ve hatta beklenmedik yerlerde ortaya çıkması ihtimali de artabilir. Bu bakımdan ülkemizin değişik havza ve akarsu yatakları için taşkın (su basma) riski haritalarının hesaplanmasında fayda vardır (Şen, 2017).

Taşkınların ülkemizde yarattığı zararın en büyük nedenlerinden biri de dere yataklarına verilen imar izni sonucu bu bölgede kurulan yerleşimin, dere yataklarının akışını bozması ve engellemesidir. Bu durumda derenin, şiddetli yağış sonucunda, debisinin artmasıyla daralan yatağından taşması ve mansabına veya denize ulaşabilmesi için önüne çıkan yerleşimi sular altında bırakması da söz konusudur (Özcan vd., 2008).

Dünya genelinde, afetlerden korunma stratejisi kapsamında afete dönüşmeden önlemlerin alınmasına olanak sağlayacak afetlere karşı risk yönetimi çalışmalarına geçilmektedir. Yine de bu yaklaşımdaki başarı, gelişmiş koruma ve uyarı sistemleri ile daha iyi afet acil durum planlaması vb. afet yönetim çalışmalarının bir arada yürütülmesine bağlı olmakla birlikte, temel yaklaşımdaki bu değişim küresel iklim değişikliklerine bağlı olarak artan taşkınların ve diğer afetlerin tahminindeki belirsizliklere de yol açmaktadır. Son zamanlarda yaşanan küresel iklim değişimi, arazi kullanımındaki değişimler gibi birçok faktör taşkın riskinin gelecekte nasıl olacağını ve bu risklerin ne kadar iyi yönetilebileceğini etkileyecektir (Kadıoğlu, 2008).

Afet risk değerlendirilmesinde bir yerleşim alanında fiziksel, sosyokültürel ve yönetsel hususların üç aşamada değerlendirilmesi gerekmektedir. Ayrıca afet tehlikesinin önlenmesi ve büyük kayıplar oluşmaması için toplumsal önlem ile faaliyetlerin afet zararlarını en asgariye indirecek şekilde planların yapılarak uygulanması gerekmektedir (Japonya Uluslararası İşbirliği Ajansı, 2008).

Devlet Su İşleri (DSİ) Genel Müdürlüğü verilerine göre Türkiye de gerekli görülen yerlerde baraj, gölet, sel kapanı, sedde, taşkın kontrol yapıları vb. gibi yapı ve tesislerde artış meydana gelmesine rağmen son 40 yılda yaklaşık 600 den fazla ölüm 800000 hektardan fazla tarım arazisi taşkına maruz kalmıştır (Mahnamfar vd., 2020).

Taşkın Yönetimi yağış, akış, su baskını gibi bilimsel ve mühendislik sorunları yanı sıra insan ve sosyo-ekonomik konularda da planlama, yönetim ve geliştirme açısından bütüncül bir yaklaşımla ele alınmalıdır. Taşkınlardan korunma veya taşkın zararlarının en asgariye indirilmesi taşkın yaşanan bölgedeki yönetim planların varlığı ve tespitiyle mümkündür ( $\mathrm{Su}$ Yönetimi Genel Müdürlüğü, 2017). 
Sistematik bir süreç olan risk yönetimi; riskin tanımlanması, risk analizi ve risk miktarının belirlenmesinden oluşur. Olası bir taşkında can ve mal kaybını en aza indirmek ve taşkının olumsuz etkilerini azaltmak için yapılması gereken öncelikle taşkın alanlarındaki risk yönetimi ile gerçekleștirilebilmektedir (Özcan, 2017).

Risk yönetimi çalışmalarında genel olarak tehlike ve riskler belirlenmekte, risk senaryoları hazırlanmakta, korunma ve zarar azaltma önlemleri seçilerek sonuçlar güncel haritalarla belirlenmektedir. Belirlenen tespit ve incelemeler sonucunda kullanılabilecek kaynak ve imkânlar belirlenerek afetten korunma ve afet müdahalesi için en uygun seçenek ve öncelikler hakkında kararlar verilerek uygulamaya geçilmektedir (Özcan, 2017).

Afetlerde zarar azaltma çalışmalarında öncelikle risk profili oluşturularak riskin gerçekleşmesinin önüne geçilmesi için tehlikelere karşı, engelleyici ya da zarar azaltıcı yönetim faaliyetlerinin oluşturulması gerekir. Risk profilinin oluşturulmasında geçmişe yönelik risk değerlendirmesi büyük önem taşımakla beraber, geçmişte yaşanmış afetler sonucu meydana gelmiş olan tehlikelerin kimleri, nasıl etkilediği, oluşan fiziki ve sosyal zararlarında öncelikli olarak değerlendirilmesi gerekir. Afet tehlikelerine karşı yapılacak olan risk yönetimi çalışmaları, yapısal ve yapısal olmayan önlemler olarak ikiye ayrılırken, yapısal önlemler; şehirlerde kentsel dönüşüm projeleri ile derelerin ıslahı gibi çalışmaları örnek verilebilir. Yapısal olmayan önlemler ise toplumda yer alan sosyal güvenlik açlklığına yönelik önleyici çalışmalar olan toplumun afete yönelik bilgilendirilmesi, eğitim çalışmaları vb. faktörlerdir (Ekşi ve Kantarlı, 2020).

Taşkın riskini ele alabilmek için bir veya birden fazla olayın belli bir konumda veya büyüklükte mevcuttaki insan durumumu ve fiziksel şartları ne ölçüde etkileyeceği durumu (insan yaşamı, maddi hasar, sosyal-ekonomik ve kültürel vb.) değerlendirmemiz gerekmektedir. Taşkın riski aşağıdaki gibi formülize edilebilir (Menteş vd., 2019).

\section{Taşkın Riski= Taşkın Tehlike x Maruziyet x Güvenlik Açığı}

Taşkın riskinin belirlenmesinde öncelikle geçmişte yaşanan tarihi taşkınlar hakkında da bilgi edinilmesi ve taşkın ön riskinin ele alınması gerekmektedir. Geçmişte yaşanmış ve taşkın riski yüksek alanlar için HEC-RAS 1 boyutlu (1B) ve 2 boyutlu (2B) hidrolik/hidrodinamik modelleme çalışmaları yapılarak taşkın tekerrür debilerine göre taşkın riski daha ayrıntılı ve karşılaştırmalı olarak ortaya konulabilir. Bu şekilde taşkın yayılım süresi, akış hızı ve su derinliği ve tehlike haritaları üretilerek taşkın risk haritaları oluşturulabilir (Taş, 2018).

Taşkın olaylarında risk analizlerinin yapılması için afet öncesi, anı ve sonrası planlamaların doğru ve uygun bir şekilde yapılabilmesi gerekmektedir. Bu kapsamda yapılması planlanan uygulamalar (bilgi, belge ve haritaların üretilmesi vb.) uzun süreçte gerçekleşeceğinden ilgili ve sorumlu Kurum/Kuruluş ve meslek gruplarının koordineli şekilde çalışması gerekmektedir.

Çalışmanın amacı, Doğu Karadeniz Havzasında yer alan Kirazlı deresi için HEC-RAS yazılımı kullanılarak yapılan $1 \mathrm{~B}$ ve $2 \mathrm{~B}$ taşkın modellemeleri ile önceden oluşturulmuş derinlik haritalarından yararlanılarak, elde edilen taşkın risk haritalarının ekonomik, sosyal olarak riskli alanlarda taşkın riskinin azaltılması için hedefler belirlenerek, uygun tedbirlerin alınması kapsamında planlamalar yapılmıştır. Bu çalışma kapsamında çalışma alanı olarak TrabzonVakfıkebir ilçe Merkezi Kirazlı deresi seçilmiştir. Çalışmada daha önce Kirazlı deresi için HEC-RAS 1B ve $2 \mathrm{~B}$ taşkın modellemeleri ile yapılmış çalışmalardan yararlanılarak oluşturulan taşkın tehlike alanlarından ve derinliklerden yararlanılmıştır. Bu haritadan taşkın riski toplam etkisinin belirlenmesi maksadıyla Q500 debisi geldiğinde etkilenebilecek kișiler ve sosyal, kültürel ve ekonomik maddi zararlar hesaplanarak oluşturulan riskli alanlarda, taşkın riskinin azaltılması için 
hedefler sunulmuştur. Bu hedeflere uygun tedbirler belirlenerek de taşkın öncesinde, taşkın esnasında ve sonrasında yapılması gereken çalışmaları içeren planlamalar yapılmıştır.

\section{MATERYAL VE YÖNTEM}

Ülkemizde son zamanlarda iklim değişikliğine bağlı olarak yaşanan ani yağışlar sonucu oluşan ani taşkınları sadece küçük derelerde ya da yan kollarda değerlendirmek yerine havza ölçeğinde değerlendirmek, taşkını etkili bir şekilde yönetmemizi ve müdahale etmemizi sağlamaktadır. Türkiye de taşkın kapsamında yetkili birçok kamu kurumu tarafından çıkarılan kanunlar, yönetmelikler, genelgeler içerisinde taşkın hususu ile ilgili maddeler yer almakla birlikte taşkın konusunda Türkiye de çalışan birçok kurumu etkilediği ve kurumlar arası koordinasyonun en iyi şekilde sağlanmasının önemini vurgulamak gerekmektedir.

Doğu Karadeniz Havzasında yer alan Kirazlı Deresinin potansiyel taşkın riski bulunduğundan, daha önceden HEC-RAS 1B ve 2B model ile elde edilen taşkın tehlike haritası kullanılarak taşkın riskinden etkilenebilecek nüfus ve ekonomik durum belirlenerek taşkın risk haritasının yapıldığı söylenebilir. Ayrıca bu çalışmada, bölgedeki taşkın riskini azaltmak için taşkın anında ve sonrasında alınabilecek önlemlerden de bahsedilmiștir.

\subsection{Proje Yerinin Tanıtılması ve Özellikleri}

Çalışma yeri olarak, yağışların fazla olması sebebiyle taşkın olaylarının sıklıkla görüldüğü Doğu Karadeniz Bölgesinde Trabzon İli, Vakfıkebir İlçe Merkezinde bulunan taşkın riski taşıyan Kirazlı dere seçilmiştir. Proje yeri olarak seçilen Trabzon ilinin gösterildiği harita Şekil 1'de belirtilmektedir (Ertürk ve Kaya, 2019).

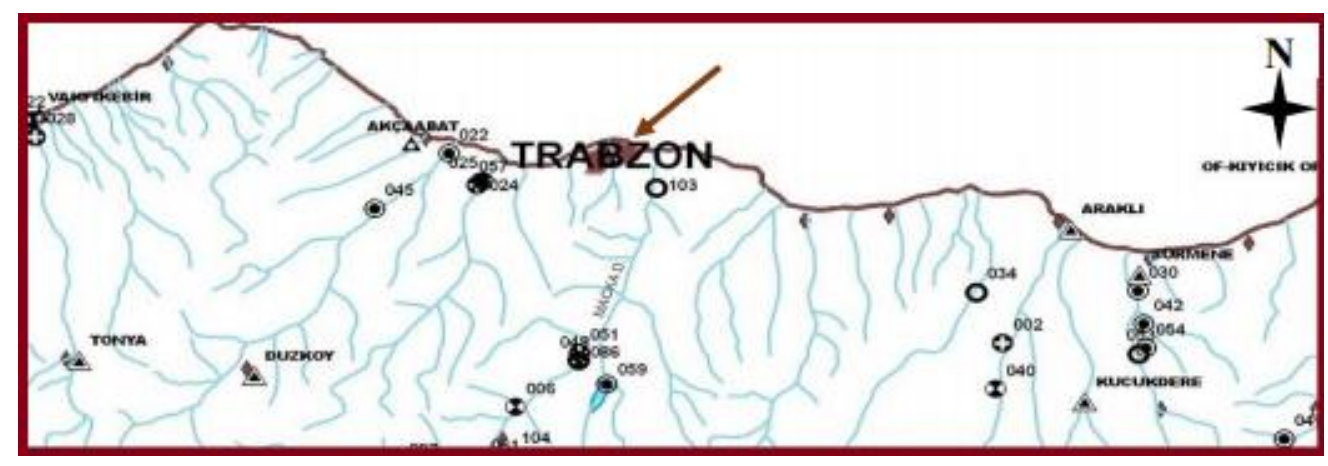

Şekil 1. Trabzon ili Vakfıkebir ilçesi Kirazlı Deresi proje yeri.

Çalışma alanı olarak belirlenen Doğu Karadeniz Havzası sınırları içerisinde yer alan Trabzon İli, Vakfıkebir İlçe Merkezi Kirazlı deresinin öncelikle HEC-RAS 1B hidrolik modelleri tamamlanarak taşkın riski taşıyıp taşımadığı tespit edilmiş, yatağından taşması sonucu HEC-RAS 2B programı ile derenin taşkın tehlike ve derinlik haritası oluşturulmuştur. Elde edilen taşkın tehlike haritaları kullanılarak da o bölgenin daha çok ekonomik olarak nasıl etkilendiğini gösteren ve bir sonraki aşama olan taşkın risk haritalarına geçilecektir (Ertürk ve Kaya, 2019).

Trabzon İli Vakfıkebir İlçesi Merkez Nüfusu, Adrese Dayalı Nüfus Kayıt Sistemi (ADNKS) bilgilerine göre 27525 kişi olarak belirlenmiş ancak ekonomik zarar hesaplanırken çalışma yeri olarak belirlenen alandan etkilenen nüfus sayısı ayrıca hesaplanmıştır. Ayrıca taşkın risk haritası belirlenirken, daha önce yapılmış olan taşkın derinlik haritasında yer alan konutlar, fabrika, sera alanları vb. yapıların sayıları, konumları ve o bölge içerisinde yaşayan nüfus sayısı da belirlenerek hasar-derinlik eğrileri kullanılarak (Huizinga vd., 2017) taşkından etkilenen nüfus ve ekonomik zarar haritası sonucu toplam risk durumu belirlenmiştir. 


\subsection{Tașkın Derinlik ve Tașkın Tehlike Haritaları}

Taşkın riski genel olarak taşkın tehlikesi, maruz kalma ve tehlikeye açık olmanın sonucu olarak tanımlanmakla beraber genellikle ekonomik kayıp olarak da ifade edilmektedir (URL-3). Taşkın risk haritası; o bölgede taşkından etkilenebilecek nüfus sayısı, etki altında kalacak ekonomik faaliyetlerin durumu, sosyo-kültürel durumları gösteren bir haritadır. Bu nedenle taşkın yaşanan bölgenin nüfusu, konut, ticari binalar, endüstriyel binalar, vb. gibi) yapıların kategorilerinin öncelikli olarak belirlenmesi gerekmektedir (URL-4).

Risk haritalarına geçmeden önce elde edilmesi gereken taşkın tehlike ve derinlik haritaları için çalışılması planlanan ve taşkın yapan nehirlerin veya derelerin yataklarının yıllar ve hatta aylar içerisinde değişimler gösterdiğinden, kullanılacak özellikle geometrik verilerin yakın zamanlarda üretilmiş olması projenin doğruluğunu ve gerçekliğini kuvvetlendirmektedir. Bu nedenle ana dere veya yan dereler üzerinde alınan kesitlerin sıklığı ne kadar artarsa haritalarda da o denli iyi sonuçlar elde edilecektir (Karaca vd, 2016). Ayrıca özellikle taşkın tehlike ve derinlik haritaları bulunurken, modelde kullanılacak sanat yapıları da belirlenerek sanat yapısının hemen öncesinde ve hemen sonrasında kesit alınması, modelleme çalışmalarının gerçeğe uygunluğunu da sağlayacaktır (URL-4).

Trabzon İli, Vakfıkebir İlçesi Kirazlı deresi HEC-RAS 1B hidrolik model uygulanınca, derenin dışına çıkan suyun yayılımı gerçekleștiğinden dolayı taşkın yaşanacak en riskli durumu belirleyebilmek için Q500 debisi olan 179,81 m3/s seçilerek HEC-RAS 2B model uygulanmıştır. Planlama yapılan alanda suyun dere dışına taşmasının ardından mevcutta bulunan 3 adet köprüde, köprülere ait açıklık, platform genişlikleri dikkate alınarak taşkın yayılımına etkilerinin ne derecede olduğu belirlenmesi için yine HEC-RAS 2B modelle hidrolik modelleme yapılmıştır. HEC-RAS 1B ve 2B hidrolik modellemelerin entegresi yapılarak Şekil 2 ve Şekil 3'te taşkından etkilenen alanlar bulunarak taşkın tehlike ve derinlik haritaları oluşturulmuştur (Ertürk ve Kaya, 2019).

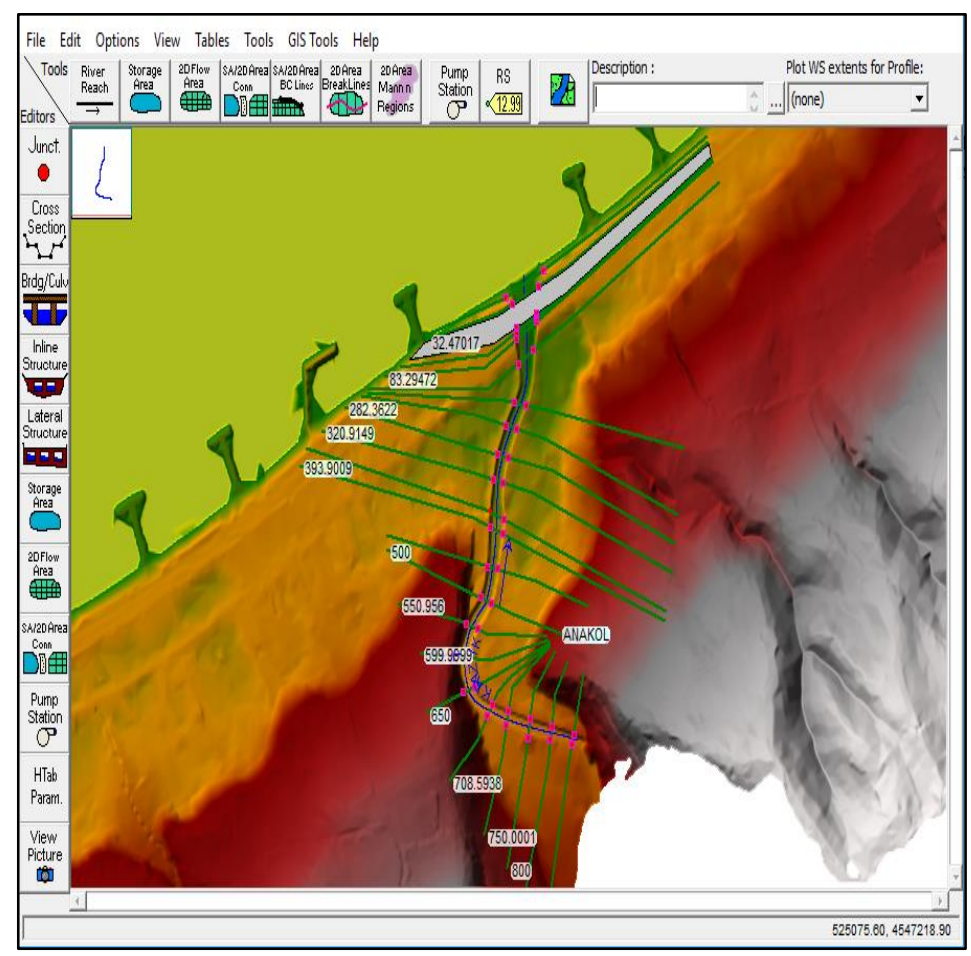

Şekil 2. HECRAS 2B modelde dere yatağı, kesit ve köprüler. 


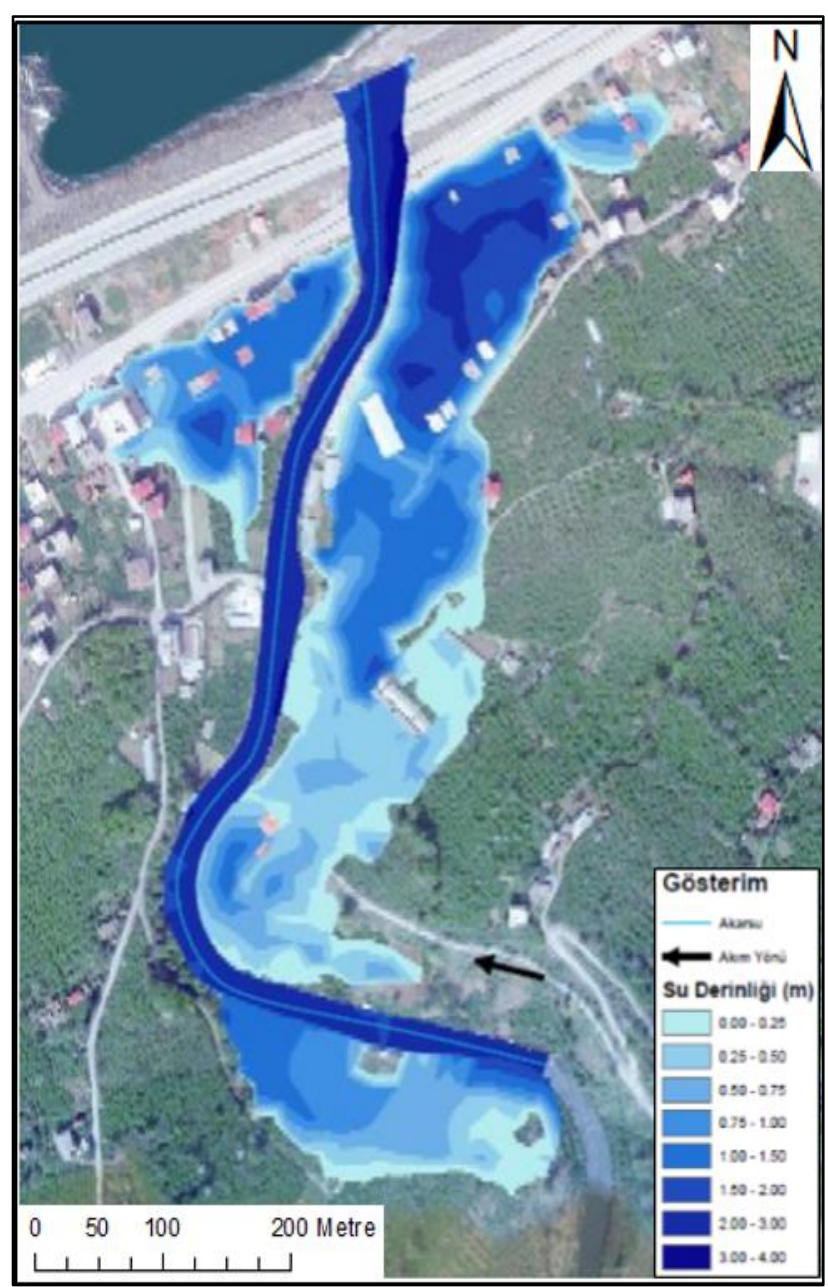

Şekil 3. HECRAS 2B modeli taşkın derinlik haritası.

\subsection{Taşkın Risk Haritaları}

Taşkın risk haritaları, taşkın ve taşkınla ilgili risklere maruz kalan bölgeler hakkında bilgi sahibi olmak için kullanılmaktadır. Böylece ulusal ve yerel yönetimler (devlet kuruluşları, belediyeler, vb.) bu haritalar doğrultusunda taşkın yönetim planlarını uygulayarak, halkı taşkınlara karşı uyarabilmekte ve alacağı önlemlerle halkı koruyabilmektedir. Ayrıca risk haritaları, risk değerlendirmesi, risk yönetimi ve risk iletişimi gibi konularda da kullanılmaktadır. Taşkın yönetim planları kapsamında, üç farklı yinelenme dönemine ait hidrograflar kullanılarak 2 boyutlu hidrolik modeller aracılığıyla hazırlanan taşkın tehlike haritaları doğrultusunda; taşkından etkilenen insan sayısı, ekonomik aktiviteler, stratejik tesisler ve olası ekonomik zararlar ile taşkında yaşanabilecek çevresel zararın boyutlarının tahmin edildiği "Taşkın Risk Haritaları" hazırlanmaktadır.

Taşkın risk haritaları, taşkının olumsuz etkilerinin gösteriminin yapıldığı haritalar olup taşkın riskinin değerlendirmesinin ana maksadı insan güvenliği, alandaki çevresel özelliklerin korunması için alınan kararlarının desteklenmesi ve hem özel kişiler ile hem de kamu yönetiminde ticari ve diğer ekonomik faaliyetlerde meydana gelebilecek zararları önlemeyi amaçlamaktır ( $\mathrm{Su}$ Yönetimi Genel Müdürlüğü, 2017).

Taşkın afetleri daha çok taşkın tehlikesi sonucu ile toplumların zafiyetlerinin (savunmasızlıklarının) ortak olarak birleşmesinden oluşur. İklim değişikliğine bağlı olarak ani yağış-akış sonucu oluşan afeti tamamen önleyemeyeceğimiz gibi taşkın tehlikesini azaltmak da 
üzerinde durulması gereken önemli bir konudur. Bu kapsamda yürütülen faaliyetler; ülke, bölge ve yerleşim birimi alanlarında olmak üzere çok geniş uygulama alanı göstermektedir. Bu konuyla ile ilgili olarak yapılacak olan diğer çalışmalar;

- Taşkın anında birden fazla Kurum/Kuruluş tarafından uygulanacak faaliyetler açısından yasal mevzuatın yeniden gözden geçirilerek eksiklerin giderilmesi,

- Taşkın yaşanması muhtemel alanların ihtiyaç duyulan kısımlarında bilimsel ve teknik araştırma-geliştirme faaliyetlerinin planlanarak uygulanması,

- Hidro-meteorolojik gözlem ağlarının genişletilmesi, bazı büyük nehir ve dereler üzerinde erken uyarı ve kontrol sistemlerinin kurularak geliştirilmesi,

- Taşkın zararlarının azaltılması konusunda kapsamlı ve anlaşılabilir düzeyde halka eğitim verilmesi,

- Taşkınlara karşı önleyici ve zarar azaltıcı yapısal tedbirlerin geliştirilmesi ve uygulanması gibi pek çok faaliyet, taşkın zarar azaltma aşamasında gereken ana faaliyetler arasında sayılmaktadır (URL-1).

\subsection{Taşkın Risk Haritaları Parametreleri}

Taşkın risk haritası unsurları; o bölgede taşkından etkilenebilecek nüfus sayısı, bölgedeki ekonomik faaliyetler ve sosyo-kültürel durumları gösteren haritalar olduğundan tehlikeye maruz kalma ve açı olmanın ürünü olarak tanımlanan taşkın risk değerlendirmesinde yaygın olarak kullanılan parametreler taşkın yayılım alanları ve derinliğidir (URL-2).

Çalışma alanı olarak seçilen taşkın bölgesinde yer alan binalar ve yapılar için, Çevre ve Şehircilik Bakanlığı tarafından yayınlanan "Mimarlık ve Mühendislik Hizmet Bedellerinin Hesabında Kullanılacak 2020 Yılı Yapı Yaklaşık Birim Maliyetleri Hakkında Tebliğ" adlı belge kullanılarak öncelikli olarak yapı yaklaşık maliyetleri belirlenmektedir. Ayrıca Yapı maliyeti zararına ek olarak, taşkın sonucu yapı içinde oluşan zarar (müştemilat zararı) da Müştemilat Zararı ve Yapı Zararı İlişkisi sonucu oluşturulan tablo aşağıda verilmiştir (Huizinga vd., 2017).

Tablo 1. Müştemilat Zararı ve Yapı Zararı İlişkisi.

\begin{tabular}{|l|l|}
\hline \multicolumn{2}{|c|}{ Müştemilat Zararı (Konutlar İçin) } \\
\hline Moel et al. (2014) & $0.50 \times$ Maksimum Konut Zararı \\
\hline Kok et al. (2005) & $0.50 \times$ Maksimum Konut Zararı \\
\hline Vanneuville et al. (2006) & $0.50 \times$ Maksimum Konut Zararı \\
\hline Penning-Rowsell et al. (2010) & $0.50 \times$ Maksimum Konut Zararı \\
\hline Chinh et al. (2017) & $0.50 \times$ Maksimum Konut Zararı $(0.60<\mathrm{h}<1.20)$ \\
\hline Chinh et al. (2017) Müştemilat Zararı (Ticari Yapılar İçin) \\
\hline \multicolumn{2}{|c|}{ Müştemilat Zararı (Endüstriyel Yapılar İçin) } \\
\hline Scawthorne et al. (2006) & $1.00 \times$ Maksimum Ticari Yapı Zarar \\
\hline FEMA (2013) & $1.50 \times$ Maksimum Endüstriyel Yapı Zararı \\
\hline \multicolumn{2}{|c|}{$1.00 \times$ Maksimum Ticari Yapı Zarar } \\
\hline Scawthorne et al. (2006) & $1.50 \times$ Maksimum Endüstriyel Yapı Zararı \\
\hline FEMA (2013) &
\end{tabular}


Çalışma alanı içerisinde belirlenen yaklaşık maliyetlere ek olarak konutlar için (0,5 x Maksimum yapı zararı), Ticari yapılar için (1,0 x Maksimum yapı zararı) ve Endüstriyel yapılar için (1,5 x Maksimum yapı zararı) alınarak müştemilat zararı da hesaplanmıştır. Ayrıca çalışılan alanda mevcut yapıların zamanla değerinin azalacağı gerçeğinden yola çıkllarak amortisman faktörü kullanılması da gerektiğinden 0,50 katsayısı da eklenerek ekonomik zarar hesaplanmıştır. Taşkın altında kalan yapıların kullanım amacı ve su derinliklerinin hesaplanmasının ardından Şekil-4'te gösterilen Joint Research Centre (JRC) tarafından 2017 yılında yayınlanan "Küresel Taşkın Derinlik-Hasar Fonksiyonları" kaynağında önerilen "derinlik - hasar" eğrileri kullanılarak her bir yapıdaki zarar oranı hesaplanmıştır. Avrupa ülkelerinde standart hasar fonksiyonlarından türetilen, taşkın derinlik-hasar fonksiyonları aşağıdaki tablo kullanılarak hesaplanmaktadır (Huizinga vd., 2017).

Tablo 2. Derinlik ve Hasar Eğrisi Değerleri (JRC, 2017).

\begin{tabular}{|c|c|c|}
\hline & Taşkın Su Derinliği (m) & Zarar Oranı (Avrupa) \\
\hline \multirow{9}{*}{ Konut } & 0 & 0 \\
\hline & 0,5 & 0,25 \\
\hline & 1 & 0,4 \\
\hline & 1,5 & 0,5 \\
\hline & 2 & 0,6 \\
\hline & 3 & 0,75 \\
\hline & 4 & 0,85 \\
\hline & 5 & 0,95 \\
\hline & 6 & 1 \\
\hline \multirow{9}{*}{$\begin{array}{c}\text { Ticari } \\
\text { Binalar }\end{array}$} & 0 & 0 \\
\hline & 0,5 & 0,15 \\
\hline & 1 & 0,3 \\
\hline & 1,5 & 0,45 \\
\hline & 2 & 0,55 \\
\hline & 3 & 0,75 \\
\hline & 4 & 0,9 \\
\hline & 5 & 1 \\
\hline & 6 & 1 \\
\hline \multirow{9}{*}{$\begin{array}{c}\text { Endüstriyel } \\
\text { Binalar }\end{array}$} & 0 & 0 \\
\hline & 0,5 & 0,15 \\
\hline & 1 & 0,27 \\
\hline & 1,5 & 0,4 \\
\hline & 2 & 0,52 \\
\hline & 3 & 0,7 \\
\hline & 4 & 0,85 \\
\hline & 5 & 1 \\
\hline & 6 & 1 \\
\hline
\end{tabular}




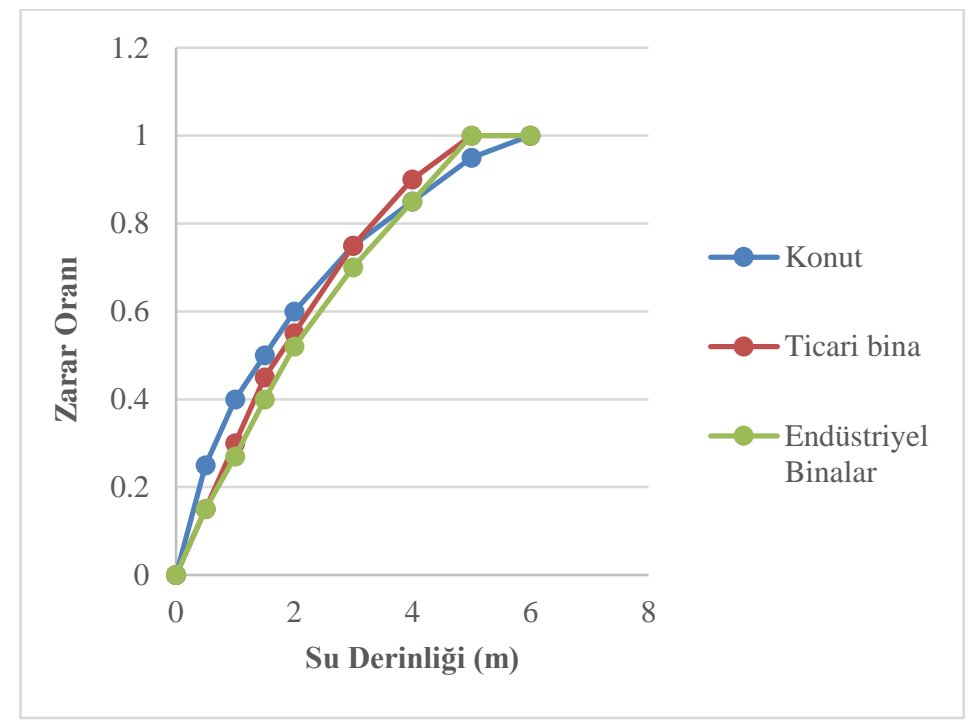

Şekil 4. Derinlik ve Hasar Eğrisi (JRC,2017).

Her bir taşkın debisi için yapıların ekonomik risk değeri aşağıda yer alan formül kullanılarak hesaplanır:

$$
Z=D R \times A \times B F \times 0.6 \times 0.5 \times 1.18
$$

Z: İlgili debide hesaplanan ekonomik zarar değeri (TL)

$D R$ : Hesaplanmış su yüksekliğine denk gelen zarar oranı

A: Yapının alanı $\left(\mathrm{m}^{2}\right)$

$B F$ : Çevre ve Şehircilik Bakanlığı tarafından yayınlanan yapı birim fiyat tebliği $\left(\mathrm{TL} / \mathrm{m}^{2}\right)$ (URL-16).

"Küresel Taşkın Derinlik-Hasar Fonksiyonları" kaynağına göre; yapılan çalışmalarda yapıları basan su yüksekliği ne olursa olsun, \%40’ının hiçbir şekilde taşkından zarar görmediği belirtilmekte olup maksimum zarar hesaplamalarında, yapıların zarar görmeyen kısmı düşünülerek 0.6 çarpanı ile azaltma yapılmıştır (Huizinga vd., 2017). Yapılan bu çalışmada iki durum ele alınarak yapıların \%60'ının zarar gördüğü düşünülerek bu doğrultuda her iki durum için toplam ekonomik zarar hesaplanmıştır.

Taşkın risk durumunu elde etmek için hesaplanan toplam ekonomik zarar değeri yapıların kendi alanlarına bölünerek birim metrekareye düşen zarar değeri (TL) yani taşkın birim zararı hesaplanmaktadır. Daha sonra hesaplanan bu değerlerin birim metrekareye düşen maksimum ve minimum zarar değerleri kullanılarak aşağıda verilen formül yardımıyla 0 ve 1 arasında normalize edilmesi gerekmektedir.

$$
x_{\text {norm }}=\frac{x-x_{\min }}{x_{\max }-x_{\min }}
$$


Burada $\mathrm{x}_{\text {norm }}$ normalize edilmiş değer, $\mathrm{x}$ normalize edilmek istenen değer, $\mathrm{x}_{\min }$ veri setinde hesaplanmış olan en küçük zarar değeri ve $\mathrm{x}_{\max }$ da hesaplanmış olan en yüksek zarar değerini ifade etmektedir. Bulunan bu değer ilgili debi $\mathrm{Q}_{500}$ için hesaplanmış olan ekonomik risk değeridir.

Proje alanı içerisinde yer alan nüfus verileri 2020 yılı (ADNKS) verileri kullanılarak hesaplanmıştır. Nüfus riski için her bir yapının yükseklikleri ve alanı göz önüne alınarak yapıların hacimleri hesaplanmış ve hesaplanan hacim değerleri de yine normalizasyon formülü kullanılarak 0 ile 1 arasında normalize edilmiştir. Taşkın riskinin elde edilmesi için önceden hesaplanan normalize edilmiş birim taşkın zararı ile yine aynı formülle elde edilen normalize edilmiş nüfus toplanarak proje alanındaki toplam taşkın riski bulunmuştur.

$$
\text { Toplam Risk= Ekonomik Risk (0-1) + Nüfus Riski (0-1) }
$$

Taşkın riski taşıyan alanlarda risk önceliklendirilmesinin de yapılması gerekmektedir. Muhtemel risk analizi hesaplanırken, afet durumunun gerçekleşme olasılığı ile afet durumunun etkisi düşünülerek yapılmalıdır. Bu durumlara göre afet yaşanan ya da yaşanması muhtemel alanlarda yapılan hesaplar sonucunda, taşkın risk yüzdelerinin belirlendiği bu çalışmada, taşkından etkilenen yapıların durumuna göre kabulü yapılan standart sapma analizi sonucu taşkın tehlike dereceleri de yüksek, düşük ve çok düşük riskli olarak belirlenmiştir.

Taşkın risk haritası oluşturulurken öncelikle çalıșma yapılacak bölge için Arc-GIS programı kullanılarak 1/5000 ölçekli imar planlarından yararlanılarak, o bölgedeki yapılar (konut, fabrika, sera) belirlenmiş ancak imar haritasında olmasına rağmen risk analizinde kullanılmayacak yapılar (yol, elektrik direkleri, su deposu vb.) çıkarılmıştır. Yine Arc-GIS programı ile taşkın derinlik haritası doğrultusunda derinlik haritasındaki yapılar ile 1/5000 ölçekli haritalar çakıştırılarak taşkın altındaki riskli alanlar belirlenmiştir. Arc-GIS programı yardımıyla elde edilen haritadaki mevcut konutlar, fabrika, sera gibi yapıların cinsi, sayıları, konumları, alanları ve su derinlikleri belirlendikten sonra riskli bölgede yaşayan nüfus durumu da analiz edilip gerekli exel hesaplamaların ardından, yapıların yaklaşık maliyetleri hesaplanarak ekonomik zarar ve risk durumları hesaplanmıştır.

Elde edilen hesaplar sonucu Trabzon İli, Vakfıkebir İlçesi Kirazlı deresi taşkın derinlik haritası üzerinde çalışılarak bulunan \%60 ekonomik zarar sonucu oluşan ve o bölgedeki yaşayan nüfusu etkileyen taşkın risk durumunu gösteren harita Şekil 5 'te verilmiştir.

Çalışma alanında yapılan risk analizi sonucu, taşkından etkilenen yapıların (konut, sera ve fabrika) nüfus ve taşkın risk durumları Tablo 3'te gösterilmiştir. Bu analize göre; taşkından etkilenen nüfusun \%34'ünün yaşadığı 15 konutta taşkın riski yüksek olarak belirlenmiştir. Ayrıca taşkından etkilenen 1 adet fabrika düşük riskli, 3 adet sera ise çok düşük riskli olarak tespit edilmiştir.

Taşkında kalan binaların su derinliğini gösterir haritadan yararlanılarak su altında kalan yapıların (konut) yüksekliklerinin maksimum 2,0 metre, minimum 0,05 metre, seralarda su altında kalan yükseklik maksimum 0,95 metre, minumum 0,15 metre ve fabrika için ise 1,30 metre olarak analiz edilmiştir. Yapılan çalışma sonucu 26 adet yapıdan (konut) 15 adeti su altında kalırken, o bölgede yaşayan nüfusun taşkından etkilenebilecek risk yüzdesi ise yüzde 59 olarak hesaplanmıştır. Proje alanında yer alan 1 adet fabrika taşkından yüzde 24 etkilenirken, 7 adet seradan sadece 3'ü taşkından etkilenerek risk yüzdesi 4 olarak hesaplanmıştır. Bu kapsamda taşkın riski taşıyan alanlarda yapılan çalışma sonucu taşkından etkilenen konutlardaki tehlike derecesinin yüksek riskli, fabrikanın düşük riskli ve seralardaki tehlike derecesinin ise çok düşük riskli olduğu görülmektedir. 


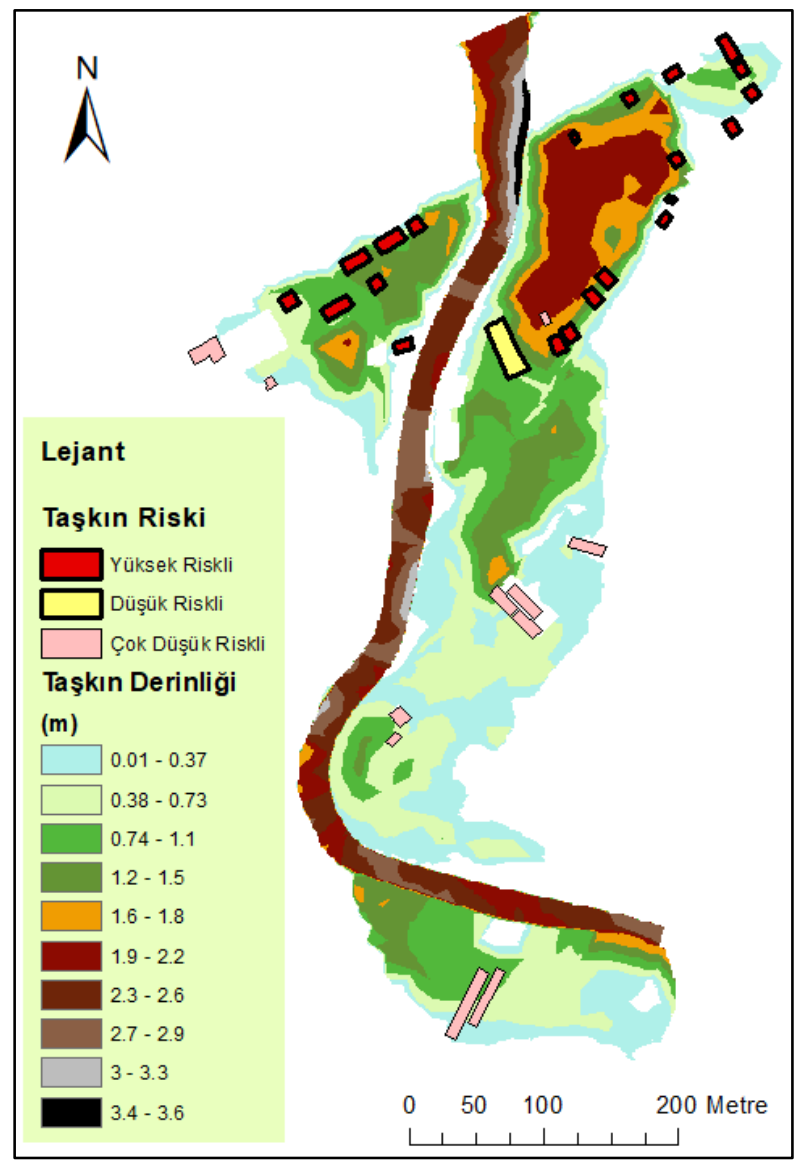

Şekil 5. Taşkın Risk Haritası.

Tablo 3. Taşkın Risk Analizi.

\begin{tabular}{|c|c|c|c|c|c|}
\hline Yapılar & Derinlik (m) & $\begin{array}{c}\text { Su Altında } \\
\text { Kalan Yapı } \\
\text { Sayısı }\end{array}$ & $\begin{array}{c}\text { Taşkından } \\
\text { Etkilenen Nüfus } \\
\text { Yüzdesi }\end{array}$ & $\begin{array}{c}\text { Taşkın Risk } \\
\text { Yüzdesi }\end{array}$ & $\begin{array}{c}\text { Tehlike } \\
\text { Derecesi }\end{array}$ \\
\hline $\begin{array}{c}\text { Yapı } \\
\text { (Konut) }\end{array}$ & $\begin{array}{c}\text { (Minimum 0,05 } \\
\text { m-Maksimum } 2 \\
\mathrm{~m} \text { ) }\end{array}$ & 15 & 34 & 59 & Yüksek Riskli \\
\hline Fabrika & $1,3 \mathrm{~m}$ & 1 & 2 & 24 & Düşük Riskli \\
\hline Sera & $\begin{array}{c}\text { (Minimum 0,15 } \\
\text { m-Maksimum } \\
0,95 \mathrm{~m} \text { ) }\end{array}$ & 3 & $<1$ & 4 & $\begin{array}{l}\text { Çok Düşük } \\
\text { Riskli }\end{array}$ \\
\hline
\end{tabular}

Söz konusu taşkın risk haritaları oluşturulurken, çalışma yapılan alanlarda ayrıca okul, hastane, kreş, kültürel, sosyal ve ekonomik aktivite yapıların bulunması durumunda, taşkın afetine maruz kalma durumunda oluşabilecek hasar ve sonuçlar, diğer yapılara göre riskli olduğundan bu yapılar için risk katsayısının artırılarak hesaplamaların yapılması ve risk durumunun da buna göre hesaplanması gerekmektedir. 
Taşkın tehlike ve risk durumunu tamamen ortadan kaldıramamakla birlikte alınabilecek önlem ve tedbirlerle kısmen de olsa kontrol altına alarak zararı en asgariye indirebiliriz. Yapılan çalışmaların ardından elde edilen sonuçlara göre taşkın yönetim faaliyetleri kapsamında gerekli önlem, denetim ve tedbirlerin alınması için taşkın öncesi, taşkın anı ve taşkın sonrası şeklinde çalışmalar yapılması gerekmektedir.

Taşkın öncesi yapılması gereken yapısal önlemler (baraj, sedde, taşkın kontrol yapıları, duvarlı taş tahkimat, geçirgen tersip bentleri, ıslah sekisi vb.) ile yapısal olmayan önlemler (yasal mevzuatın düzenlenmesi, dere ve nehirler için erken-uyarı sistemleri kurulması, hidro-meteorolojik gözlem ağının genişletilmesi, Ar-Ge Çalışmaları yapılması, halkın bilinçlendirilmesi vb.) olarak gerekli çalışmalar yapılması gerekmektedir. Taşkın anında ise taşkına maruz kalan yerleşimlere gerekli yardımın ulaştırılarak kurtarma faaliyetlerinin zamanında gerçekleştirilmesi için taşkın zararları etkilerin azaltılması açısından ilgili ve sorumlu kurum ve kuruluşların koordineli çalışması gerekmektedir. Taşkın sonrasında ise taşkından etkilenmiş ve zarar görmüş yerleşim birimlerinde iyileştirme ve yenilenme çalışmaları yapılarak zararın etkilerinin giderilmesi sağlanmalıdır.

$\mathrm{Bu}$ iyileştirme ve yenilenme çalışmaları içerisinde, yerinde yapılan hasar tespiti sonrası taşkında yıkılan ve zarar gören tüm yapı ve tesislerin gerekli görülen yerlerde yapıların yeniden inşası, kalıcı konutların yapılarak yeni yerleşim planlarının hazırlanması, toplumun taşkın nedeniyle etkilenen ekonomik-sosyal ve psikolojik bütünlüğünün yeniden kazanması gibi çeşitli faaliyetler bu aşamada yapılmaktadır.

\section{SONUÇLAR VE ÖNERÍLER}

Taşkın olaylarının sıklıkla yaşandığı bir bölge olan Doğu Karadeniz Bölgesi’nde taşkının zararını asgariye indirmek maksadıyla genel olarak yapısal tedbirler alınarak taşkın kontrolü çalışmaları yapılmaktadır. Çalışma yapılan alan olarak seçilen Trabzon ili, Vakfıkebir ilçesinde yer alan Kirazlı deresi Doğu Karadeniz Bölgesinde taşkın riski taşıyan dereler arasında yer almaktadır. Bu sebeple Kirazlı deresinin taşkın risk durumunu belirlemek amacıyla, taşkın tehlike ve derinlik haritaları kullanılarak muhtemel taşkın yaşanması durumunda 26 adet yapı (konut), 7 adet sera ve 1 adet fabrikanın yer aldığı bölgede taşkından etkilenebilecek yapıların risk durumunu belirlemek amacıyla bu çalışma yapılmıştır. Çalışma sonucunda elde edilen taşkın risk haritasında, Kirazlı dere yatağının 179,81 m3/s olan Q500 taşkın debisini geçiremediği ve taşan suların sağ sahilden başlayarak mansaptaki yerleşimlere kadar bölgeyi etkilediği gösterilmiştir. Bu kapsamda çalışma yapılan alanda taşkından etkilenen 34 yapının (konut, sera ve fabrika) nüfus ve risk durumları analiz edilmiştir. Bu analize göre; taşkından etkilenen nüfusun \%34'ünün yaşadığı 15 konutta taşkın riski yüksek olarak belirlenmiştir. Ayrıca taşkından etkilenen 1 adet fabrika düşük riskli, 3 adet sera ise çok düşük riskli olarak tespit edilmiştir.

Yapılan değerlendirmeler sonucu; Kirazlı deresi için belirli kısımlarda gerekli taşkın kontrol yapıları ile mevcut sanat yapılarının da yeniden yapılması veya iyileştirilmesi gibi yapısal tedbirler önerilebilir. Ayrıca Kirazlı deresinde yılda bir kez olmak üzere düzenli olarak yatak temizliği yapılması da gerekmektedir. Yapısal tedbir olarak önerilen taşkın kontrol tesislerinin taşkının yaratabileceği zararları azaltacak şekilde yapılması önemli olduğundan, yapılan tesislerin o bölgede yaşayan halkın rutin yaşamını da aksatıp zorlaştırmaması ve estetik bir şekilde inşa edilmesi gerekmektedir. Ayrıca gerekmesi durumunda dere üzerinde taşkın erken- uyarı sisteminin kurulması ve taşkın zararlarının azaltılması konusunda da kapsamlı ve anlaşılabilir düzeyde halka eğitim verilmesinin faydalı olacağı düşünülmektedir. 


\section{KAYNAKLAR}

Ekşi, A., Kantarlı, İ. C. (2020). Su Taşkınlarına Karşı Stratejik Risk Yönetimi İzmir İli Örneği. Hastane Öncesi Dergisi. 5(1): 11-27.

Ertürk E., Kaya N. (2019). Taşkın Tehlike Alanlarının Oluşturulması: Trabzon İli Vakfıkebir İlçesi Kirazlı Deresi Örneği. Fırat Üniversitesi Mühendislik Bilimleri Dergisi, 31(2), 337-344,2019.

Huizinga, J., Moel, H. de, Szewczyk, W. (2017). Global flood depth-damage functions. Methodology and the database with guidelines. EUR 28552 EN. doi: 10.2760/16510

Karaca C., Birdal A., \& Türk T. (2016). Taşkın Risk Alanlarının Coğrafi Bilgi Sistemleri ile İncelenmesi. 6. Uzaktan Algllama-CBS Sempozyumu (UZAL-CBS 2016), 5-7 Ekim 2016, Adana.

Mahnamfar, F., Moradi Y. A. \& Ağıralioğlu, N. (2020). Flood Risk Analysis of Residential Areas at Downstream of the Elmali Dam. Academic Platform Journal of Natural Hazards and Disaster Management, 1(1), 49-58.

Menteş E., Kaya Ş., Tanık A. \& Gazioğlu C. (2019). Calculation of Flood Risk Index for Yeşilırmak Basin. International Journal of Environment and Geoinformatics, 6(3):288-299.

Özcan O., (2007). Sakarya Nehri Alt Havzası'nın Taşkın Risk Analizinin Uzaktan Algılama ve CBS ile Belirlenmesi. Yüksek Lisans Tezi, Bilişim Enstitüsü, İstanbul.

Özcan O., Musaoğlu N., D.Z. \& Tanık A. (2008). Determination of Flood risk in Sakarya Sub basin using remotely sensed data and GIS. Fresen Environment. 17 (11b), 1964-1971.

Özcan 0.,(2017). Taşkın Tespitinin Farklı Yöntemlerle Değerlendirilmesi: Ayamama Deresi Örneği. Artvin Çoruh Üniversitesi Doğal Afetler Uygulama ve Araştırma Merkezi. Doğal Afetler ve Çevre Dergisi, 3(1), 9-27. doi: 10.21324/dacd.267200.

Sarıgül, O., Turoğlu, H. (2020). Kahramanmaraş Şehri Sel ve Taşkınlarının Coğrafi Analizi ve Öngörüler. Coğrafya Dergisi Journal of Geography, (40).

Sen, Z. (2017). Taşkın ve Kuraklık Çeşitleri. İstanbul, Türkiye: Su Vakfı.

Taş, E., (2018). Coğrafi Bilgi Sistemleri Teknikleri Kullanılarak Taşkın Risk Potansiyelinin Değerlendirilmesi: Afyonkarahisar Çay Deresi Havzası. İklim Değiş̧ikliği ve Çevre, 3, (1).

T.C. Orman ve Su İșleri Bakanlığı (mülga)- Su Yönetimi Genel Müdürlüğü. (2017). Taşkın Yönetimi.

T.C. İç İşleri Bakanlığı - Japonya Uluslararası İşbirliği Ajansı (Japan International Cooperation Agency, (JICA). (2008). Afet Zararlarını Azaltmanın Temel İlkeleri.

URL-1: T.C. Tarım Ve Orman Bakanlığı Su Yönetimi Genel Müdürlüğü. (2018). Sakarya Havzası Taşkın Yönetim Planı, (1, (247-253), 589), https://www.tarimorman.gov.tr/SYGM/Belgeler/Ta\%C5\%9Fk\%C4\%B1n\%20Y\%C3\%B6netim \%20Planlar\%C4\%B1/5)\%20SAKARYA\%20HAVZASI\%20TA\%C5\%9EKIN\%20YONETIM\%20PL ANI.pdf

URL-2: T.C. Tarım T.C. Tarım Ve Orman Bakanlığı Su Yönetimi Genel Müdürlüğü. (2019). Batı Karadeniz Havzası Taşkın Yönetim Planı, (5-1, 5-2), 
https://www.tarimorman.gov.tr/SYGM/Belgeler/Taşkın\%20Yönetim\%20Planları/Batı\%20Kar deniz\%20Taşkın\%20Yönetim\%20Planları.pdf

URL-3: T.C. Tarım Ve Orman Bakanlığı Su Yönetimi Genel Müdürlügü. (2019). Kızılırmak Havzası Taşkın Yönetim Planı, (4-91, 4-92),

https://www.tarimorman.gov.tr/SYGM/Belgeler/Tașkın\%20Yönetim\%20Planları/7)\%20KIZILI RMAK\%20\%20HAVZASI\%20TASSIN\%20YONETIM\%20PLANI.pdf

URL-4: T.C. Tarım Ve Orman Bakanlığı Su Yönetimi Genel Müdürlüğü. (2020). Doğu Karadeniz Havzası Taşkın Yönetim Planı, (4-1, 5-1, 5-2),

https://www.tarimorman.gov.tr/SYGM/Belgeler/Tașkın\%20Yönetim\%20Planları/Doğuı\%20Ka rdeniz\%20Tașkın\%20Yönetim\%20Planları.pdf

Yılmaz C., Kaya M. (2020). Şehir Coğrafyası ve Afet Yönetimi Bağlamında Samsun-Atakum Sel ve Taşkınları. Doğu Coğrafya Dergisi, 25(44), 31-46. 